\title{
Measuring the atmospheric organic aerosol volatility distribution: a theoretical analysis
}

\author{
E. Karnezi ${ }^{1}$, I. Riipinen ${ }^{2}$, and S. N. Pandis ${ }^{1,3,4}$ \\ ${ }^{1}$ Department of Chemical Engineering, Carnegie Mellon University, Pittsburgh, USA \\ ${ }^{2}$ Department of Applied Environmental Studies, Stockholm University, Stockholm, Sweden \\ ${ }^{3}$ Department of Chemical Engineering, University of Patras, Patra, Greece \\ ${ }^{4}$ Inst. of Chemical Engineering Sciences, FORTH/ICEHT, Patra, Greece \\ Correspondence to: S. N. Pandis (spyros@ chemeng.upatras.gr)
}

Received: 7 October 2013 - Published in Atmos. Meas. Tech. Discuss.: 28 January 2014

Revised: 20 July 2014 - Accepted: 22 July 2014 - Published: 16 September 2014

\begin{abstract}
Organic compounds represent a significant fraction of submicrometer atmospheric aerosol mass. Even if most of these compounds are semi-volatile in atmospheric concentrations, the ambient organic aerosol volatility is quite uncertain. The most common volatility measurement method relies on the use of a thermodenuder (TD). The aerosol passes through a heated tube where its more volatile components evaporate, leaving the less volatile components behind in the particulate phase. The typical result of a thermodenuder measurement is the mass fraction remaining (MFR), which depends, among other factors, on the organic aerosol (OA) vaporization enthalpy and the accommodation coefficient. We use a new method combining forward modeling, introduction of "experimental" error, and inverse modeling with error minimization for the interpretation of TD measurements. The OA volatility distribution, its effective vaporization enthalpy, the mass accommodation coefficient and the corresponding uncertainty ranges are calculated. Our results indicate that existing TD-based approaches quite often cannot estimate reliably the OA volatility distribution, leading to large uncertainties, since there are many different combinations of the three properties that can lead to similar thermograms. We propose an improved experimental approach combining TD and isothermal dilution measurements. We evaluate this experimental approach using the same model, and show that it is suitable for studies of OA volatility in the lab and the field.
\end{abstract}

\section{Introduction}

Atmospheric aerosol particles play an important role in the Earth's energy balance by absorbing and scattering solar radiation (direct effect) and influencing the properties and lifetime of clouds (indirect effects) (IPCC, 2007). They have significant negative effects on human health, including premature death, increases in respiratory illnesses, and cardiopulmonary mortality (Nel, 2005; Pope and Dockery, 2006).

Aerosols contain a wide variety of inorganic and organic compounds, with organics representing about $50 \%$ of the fine $(<1 \mu \mathrm{m})$ aerosol mass (Zhang et al., 2007). Organic aerosol $(\mathrm{OA})$ originates from many different natural and anthropogenic sources and processes. It can be emitted directly, e.g., from fossil fuels and biomass combustion (so-called primary organic aerosol), or formed by atmospheric oxidation of volatile organic compounds (VOCs) (secondary organic aerosol, SOA). Since the oxidation pathways for VOCs are complex and the reactions lead to hundreds or thousands of oxygenated products, our understanding of organic aerosol formation mechanisms and the OA chemical and physical properties is still incomplete.

The volatility of atmospheric OA is one of its most important physical properties. It determines the partitioning of these organic compounds between the gas and particulate phases, and the organic aerosol concentration, and influences the rate of reactions and the atmospheric fate of the corresponding compounds. Measurement of the OA volatility distribution has been recognized as one of the major challenges in our efforts to quantify the rates of formation of secondary organic particulate matter (Donahue et al., 2012). 
OA consists of thousands of compounds, too few of which have been identified. The volatility basis set framework (Donahue et al., 2006) was developed to describe absorptive partitioning by lumping all these compounds into surrogates along an axis of volatility. This approach typically employs species with effective saturation concentrations at $298 \mathrm{~K}$ separated by one order of magnitude (bin), with values ranging from, say, 0.01 to $10^{6} \mu \mathrm{g} \mathrm{m}^{-3}$. By quantifying the volatility distributions of primary and secondary OA, a physically reasonable description of semi-volatile organics that is still suitable for large-scale chemical transport models can be obtained (Pathak et al., 2007; Stanier et al., 2008).

Thermodenuders (TD) have been developed to measure the volatility of ambient aerosol (Burtscher et al., 2001; Wehner et al., 2002, 2004; Kalberer et al., 2004; An et al., 2007). A TD consists of two basic parts: a heated tube where the more volatile particle components evaporate, leaving less volatile species behind, and the denuder tube containing usually activated carbon where the evaporated material is adsorbed, avoiding potential re-condensation when the sample is cooled to room temperature. The aerosol mass fraction remaining (MFR) at a given temperature, after passing through the TD, is the most common way of reporting the TD measurements.

The measurement of the volatility of OA has received considerable attention recently, and has been carried out both in the field (Engler et al., 2007; Huffman et al., 2009; Lee et al., 2010; Cappa and Jimenez, 2010) and in the laboratory (An et al., 2007; Jonsson et al., 2007; Saleh et al., 2008; Faulhaber et al., 2009). One of the main issues related to the use of thermodenuders is whether equilibrium is reached in the heating section of the instrument. Saleh et al. (2008) used high organic aerosol concentrations, allowing the model organic aerosol in their experiments to reach equilibrium in their TD. Using their integrated volume method, they were then able to determine the saturation concentration of the corresponding organic particles. Riipinen et al. (2010) showed that equilibration times in TDs depend on many factors, such as the organic aerosol loading and the accommodation coefficient. These authors argued that OA practically never reaches equilibrium in a TD at ambient concentration levels. For laboratory measurements, equilibrium can be reached with the use of high organic aerosol loadings (larger than $200 \mu \mathrm{g} \mathrm{m}^{-3}$ ), and when the residence time in the heated section of the TD exceeds $30 \mathrm{~s}$ (Riipinen et al., 2010; Saleh et al., 2011). An et al. (2007) introduced an improved TD allowing for larger residence times. Lee et al. $(2010,2011)$ performed thermodenuder experiments at two residence times, and argued that multiple residence times are needed in order to decouple mass transfer effects from thermodynamics. Similar conclusions were reached by Riipinen et al. (2010) and Cappa (2010). Saleh et al. (2012) used a particle concentrator before passing the ambient aerosol through the thermodenuder to increase the aerosol concentration levels and to reduce the equilibration timescale. Volatility measurements on longer timescales, where equilibrium of the system can be reached, have been performed by Grieshop et al. (2009).

Dynamic aerosol evaporation models (Riipinen et al., 2010; Cappa, 2010; Fuentes and McFiggans, 2012) are needed in most cases for the interpretation of TD measurements and the estimation of OA volatility. However, the MFR of OA in a TD depends not only on its volatility distribution, but also on the vaporization enthalpy and potential mass transfer resistances as the particles evaporate. The inversion of the TD measurements to calculate the OA volatility distribution has proven to be challenging because of the many parameters affecting the resulting MFR.

Previous studies have assumed a priori values for the effective vaporization enthalpy and the mass accommodation coefficient in order to estimate the OA volatility. Lee et al. (2010) tried to measure the volatility of ambient OA assuming values for the vaporization enthalpy and the accommodation coefficient equal to $80 \mathrm{~kJ} \mathrm{~mol}^{-1}$ and 0.05 , respectively. They used the time-dependent evaporation model by Riipinen et al. (2010), with least-squares minimization, to reproduce ambient measurements collected in the eastern Mediterranean. For most measurements, it was difficult to estimate the volatility distribution, especially for the less volatile components. Moreover, a change in the accommodation coefficient from 0.05 to 1 resulted in a shifting of the estimated volatility distribution by one order of magnitude. Lee et al. (2011) used the same mass transfer model in order to reproduce experimental measurements from different precursors, assuming values for the vaporization enthalpy and the accommodation coefficient. Cappa (2010) developed a new model of evaporation in a TD accounting for the cooling section and the velocity profile across the TD tube. They demonstrated the importance of the vaporization enthalpy, especially for values less than $100 \mathrm{~kJ} \mathrm{~mol}^{-1}$. They also underlined the importance of constraining the value of accommodation coefficient in order to quantify the volatility distribution of OA. Cappa and Jimenez (2010) used the model of Cappa (2010) to quantify the volatility distribution of ambient OA in Mexico City using measurements from the MILAGRO (Megacity Initiative: Local And Global Research Observations) campaign. Assuming several values for the vaporization enthalpy, either using the relationship from Epstein et al. (2010) or assuming that the vaporization enthalpy depended linearly on temperature or that it had constant values from 50 to $150 \mathrm{~kJ} \mathrm{~mol}^{-1}$, they estimated different volatility distributions. Changing the value of the accommodation coefficient from 1 to 0.1 , the estimated volatility distribution was shifted to higher values by approximately one order of magnitude. Fuentes and McFiggans (2012) used a dynamic aerosol evaporation model and the Epstein et al. (2010) relationship for the vaporization enthalpy, to calculate the volatility distribution for a-pinene SOA together with a small value of the accommodation coefficient. The estimation of the accommodation coefficient during the evaporation of atmospheric OA has been the focus of a number of studies. 
Saleh et al. (2012) developed a method combining a particle concentrator (in order to achieve high mass loadings) and a thermodenuder. Using the thermodenuder model by Saleh et al. (2011), they measured the effective evaporation coefficient of ambient aerosol. Their results suggested accommodation coefficients with values around 0.3 for the ambient particles that they examined. Cappa and Wilson (2011) focused on the evolution of organic aerosol mass spectra from lubricating oil and secondary aerosol from a-pinene oxidation upon heating, using the Cappa (2010) model. They adopted volatility distributions from previous studies (Pathak et al., 2007; Grieshop et al., 2009), and a vaporization enthalpy based on the Epstein et al. (2010) relationship. One of their major conclusions was that there were high mass transfer resistances (estimated accommodation coefficients on the order of $10^{-4}$ ) during the evaporation of the a-pinene SOA.

The sensitivity of TD results to several additional parameters has also been investigated in past studies. Lee et al. (2010) concluded that a monodisperse approximation using one effective value for the diameter of the particles instead of the full distribution resulted in changes in the thermograms of less than $2 \%$. Lee et al. (2011) explored the effect of the cooling section and the role of surface free energy, and Cappa (2010) the role of the assumed value for the diffusion coefficient or the average effective diameter of the particles. Once again, the conclusion was that these parameters were not as important as the vaporization enthalpy and the accommodation coefficient for the estimation of the volatility distribution. Recondensation in the cooling section has been investigated in a number of studies (Cappa, 2010; Saleh et al., 2011; Fuentes and McFiggans, 2012). Fuentes and McFiggans (2012), through a parametric analysis, concluded that recondensation depends on a combination of factors, such as the mass loading, the particle size and the kinetic coefficient for re-condensation. Cappa (2010) showed that recondensation becomes significant for large aerosol loadings (larger than $200 \mathrm{\mu g} \mathrm{m}^{-3}$ ); thus, it is a problem mostly for laboratory experiments. Saleh et al. (2011) showed that a configuration with a small diameter for the cooling section can lead to negligible recondensation, even for higher aerosol loadings.

In this study, we explore methods for estimating the OA volatility distribution, together with the effective vaporization enthalpy and mass accommodation coefficient. We develop a method combining forward modeling with known values for the three properties that we will try to estimate, introduction of random "experimental" error and, finally, inverse modeling with least-squares error minimization for the estimation of the OA volatility distribution, its effective vaporization enthalpy and the mass accommodation coefficient. We show that the best fit does not correspond to the most accurate estimate, due to the multiple local minima occurring in this problem. We propose an approach of estimating an ensemble of solutions, and use them to derive a best guess and corresponding uncertainties for each of the three properties. Experimental approaches to improve these estimates and to reduce the corresponding uncertainties are explored. We examine the utility of using two residence times, using isothermal dilution instead of thermodenuder measurements (Grieshop et al., 2009), and finally combining TD and isothermal dilution measurements.

\section{Thermodenuder model}

We use the mass transfer model of Riipinen et al. (2010) modeling the time-dependent evaporation of multicomponent aerosol particles by solving the mass transfer equations for a monodisperse population of particles suspended in air. We assume a monodisperse population of particles. Lee et al. (2010) showed with the use of the same mass transfer model that this simplification resulted in errors of only a few percent $(2 \%)$, and it reduced the computational time considerably. The mass flux of compound $i$ from the gas phase to the particles, $I_{i}$, is calculated by (Seinfeld and Pandis, 2006)

$I_{i}=\frac{2 \pi d_{\mathrm{p}} M_{i} \beta_{\mathrm{m} i} D_{i}}{R T_{\mathrm{TD}}}\left(p_{i}-p_{i}^{0}\right)$,

where $d_{\mathrm{p}}$ is the particle diameter, $R$ the ideal gas constant, $M_{i}$ and $D_{i}$ the molecular weight and diffusion coefficient of compound $i$ in the gas phase at temperature $T_{\mathrm{TD}}$ (the temperature in the heated part of the TD), and $p_{i}^{0}$ and $p_{i}$ are the partial vapor pressures of $i$ at the particle surface and far away from the particle, respectively. In our simulations, we assume a particle diameter of $200 \mathrm{~nm}$, a molecular weight of $0.2 \mathrm{~kg} \mathrm{~mol}^{-1}$ and a diffusion coefficient of $10^{-5} \mathrm{~m}^{2} \mathrm{~s}^{-1}$.

The mass flux is corrected for kinetic and transition regime effects with the factor $\beta_{\mathrm{m} i}$ (Fuchs and Sutugin, 1970):

$\beta_{\mathrm{m} i}=\frac{1+K n_{i}}{1+\left(\frac{4}{3 a_{\mathrm{m} i}}+0.377\right) K n_{i}+\frac{4}{3 a_{\mathrm{m} i}} K n_{i}^{2}}$,

where $K n_{i}$ is the Knudsen number, that is, the ratio of the mean free path of vapor $i$ and the particle radius, and $a_{\mathrm{m} i}$ the mass accommodation coefficient of $i$ on the particles. The mean free path is estimated by

$\lambda_{i}=\frac{3 \cdot D_{i}}{\bar{c}}$,

where $\bar{c}$ is the mean velocity of the gas molecules, given by

$\bar{c}=\sqrt{\frac{8 \cdot R \cdot T_{\mathrm{TD}}}{\pi \cdot M_{i}}}$.

The partial vapor pressure of $i$ at the particle surface, $p_{i}^{0}$, is given by

$$
\begin{aligned}
p_{i}^{0} & =x_{i} \gamma_{i} p_{\mathrm{sat}, i} \exp \left(\frac{4 M_{i} \sigma}{R T_{\mathrm{p}} \rho d_{p}}\right) \\
& =x_{\mathrm{m} i} \frac{C_{i}^{*} R T_{\mathrm{TD}}}{M_{i}} \exp \left(\frac{4 M_{i} \sigma}{R T_{\mathrm{p}} \rho d_{p}}\right),
\end{aligned}
$$


where $x_{i}$ is the mole fraction and $\gamma_{i}$ the activity coefficient of $i$ in the particle phase, $p_{\text {sat }, i}$ the pure-component vapor pressure of $i$ over a flat surface, $T_{\mathrm{p}}$ the particle temperature, $C_{i}^{*}$ represents the effective saturation concentration of $i$ in the volatility basis set (Donahue et al., 2006), and $x_{\mathrm{m} i}$ is the mass fraction of $i$ in the particle. In this study, we will be using a fixed basis set with four volatility bins, with effective saturation concentrations of $0.01,0.1,1$ and $10 \mu \mathrm{g} \mathrm{m}^{-3}$ for each volatility bin. We assume a surface tension of $0.05 \mathrm{~N} \mathrm{~m}^{-1}$ as a median of the range used in Riipinen et al. (2010). We repeated our simulations with values of $0.05-0.2 \mathrm{~N} \mathrm{~m}^{-1}$ for the surface energy, but this choice had practically no effect on the results, since the particles examined are too big and the Kelvin effect is not important. We also use a density of the surrogate compounds of $1500 \mathrm{~kg} \mathrm{~m}^{-3}$.

The saturation concentrations of the evaporating species at $T_{\mathrm{TD}}$ are estimated using the integrated form of the ClausiusClapeyron equation:

$$
\begin{aligned}
& C_{i}^{*}\left(T_{\mathrm{TD}}\right)= \\
& C_{i}^{*}(298 K) \exp \left[\frac{\Delta H_{\mathrm{vap}, i}}{R}\left(\frac{1}{298}-\frac{1}{T_{\mathrm{TD}}}\right)\right]\left(\frac{298}{T_{\mathrm{TD}}}\right),
\end{aligned}
$$

where $\Delta H_{\mathrm{vap}, i}$ is the vaporization enthalpy of species $i$. The temperature dependence of the diffusion coefficients of the evaporating species is taken into account by using

$$
D_{i}\left(T_{\mathrm{TD}}\right)=D_{i}(298)\left(\frac{T_{\mathrm{TD}}}{298}\right)^{\mu},
$$

where $\mu$ is a constant usually ranging from 1.5 to 2.0 (Chen and Othmer, 1962). We used the value of 1.75 for all the studied compounds.

The time-dependent evaporation of the organic aerosol is simulated by solving the differential equations for total particle mass $m_{\mathrm{p}}$ and gas phase concentrations $C_{i}$ of the evaporating species:

$$
\frac{\mathrm{d} m_{\mathrm{p}}}{\mathrm{d} t}=-\sum_{i=1}^{n} I_{i} \quad \frac{\mathrm{d} C_{i}}{\mathrm{~d} t}=I_{i} \cdot N_{\mathrm{tot}},
$$

where $N_{\text {tot }}$ is the total number concentration of the particles (assuming a monodisperse particle population). The MFR is then calculated from the ratio of the particle mass at $t=t_{\text {res }}$ (where $t_{\text {res }}$ is the residence time through the heating tube) to the initial mass of the particles. In this work, we study the evaporation of particles in a TD independently of the TD design and geometry: the only variables representing the instrument are the particle residence time and the temperature of the thermodenuder. We neglect the velocity and potential temperature gradients in the radial direction and thus focus on the particles moving along the centerline of the TD and at the corresponding centerline temperature. Saleh et al. (2011) showed that a similar model neglecting the radial dependence of the system reproduced well the behavior of model particles consisting of dicarboxylic acids.
We use, as inputs, values for the geometry of the TD (the length and the residence time in the heated tube), the temperature inside the TD $\left(T_{\mathrm{TD}}\right)$, the initial mass concentration of the organic aerosol $\left(C_{\mathrm{aer}}\right)$, and the properties of the organic compounds (such as the volatility distribution, vaporization enthalpy, accommodation coefficient, etc.). For the description of the geometry of the TD, we used the values for the Carnegie Mellon TD of Lee et al. (2010). Specifically for the heated tube, we used a length of $55 \mathrm{~cm}$ and a centerline residence time of $17 \mathrm{~s}$.

Using the mass transfer model of Riipinen et al. (2010), modeling the time-dependent evaporation of multicomponent aerosol particles, we constructed theoretical thermograms (MFR versus $T_{\mathrm{TD}}$ ). Previous studies have often assumed that thermograms can be directly connected to the volatility of OA. Figure 1 indicates that we can have very similar thermograms for organic aerosols with very different volatilities (orders of magnitude different). In this example, the reduction in the saturation concentration is balanced by changes in the accommodation coefficient and the vaporization enthalpy. The similarity of these suggests that the inversion of the thermograms in order to calculate the OA volatility will be very challenging.

\subsection{Pseudo-experimental data}

In order to evaluate how well we can estimate the volatility distribution, we used "pseudo-experiments" corrupting the output of the TD model, for systems with known volatility distributions and properties, with randomly generated "experimental" errors. In this way, we could take into account the measurement uncertainty due to the variability of measurement conditions, and produce relatively realistic "experimental results" for systems with known volatility distributions and properties. We "corrupted" the TD model predictions with random errors assuming a normal distribution, based on the variability of laboratory measurements with the same TD conducted by Paciga and Pandis (2014), with a standard deviation given by

$\sigma=0.51 \cdot \mathrm{MFR}_{\text {true }}-0.5 \cdot \mathrm{MFR}_{\text {true }}^{2}$,

where $\mathrm{MFR}_{\text {true }}$ are the correct MFR values. A typical example is shown in Fig. 2.

In the rest of the inversion approaches, pseudoexperimental data were used. In this way, the experimental uncertainty was always taken into account, and an overestimation/underestimation of the corresponding algorithm is avoided.

\subsection{Optimum OA volatility distribution}

The MATLAB least-squares fitting algorithm lsqcurvefit was used in order to obtain the best possible fit between the "measured" and modeled MFRs. Four lognormally equally spaced volatility bins were used, with volatilities from $10^{-2}$ 


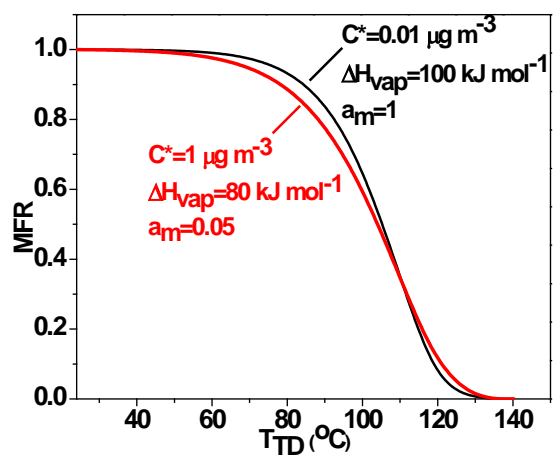

Figure 1. Predicted thermograms (MFR versus $T_{\mathrm{TD}}$ ) for OA with different properties. A single-component aerosol $\left(C^{*}=1 \mu \mathrm{g} \mathrm{m}^{-3}\right.$, $\Delta H_{\mathrm{vap}}=80 \mathrm{~kJ} \mathrm{~mol}^{-1}$ and $\left.a_{\mathrm{m}}=0.05\right)$ gives practically the same thermogram as one with a much lower volatility $\left(C^{*}=0.01 \mu \mathrm{g} \mathrm{m}^{-3}\right.$, $\Delta H_{\mathrm{vap}}=100 \mathrm{~kJ} \mathrm{~mol}^{-1}$ and $\left.a_{\mathrm{m}}=1\right)$.

to $10 \mu \mathrm{g} \mathrm{m}^{-3}$. The corresponding volatility distribution, vaporization enthalpy and mass accommodation coefficient were estimated by the algorithm minimizing the sum of the squared differences between the MFR model predictions and the pseudo-measurements. In the least-squares optimization, a total of 12 pseudo-measurements was used in all cases.

A wide variety of compositions was tested during the simulations, including one-component, two-component or multicomponent aerosols with various volatility distributions and with different values for the vaporization enthalpy and the accommodation coefficient. The results for three of these tests that are used as illustrative examples are shown in Table 1 . For Test 1 corresponding to OA consisting of very low and high volatility material $\left(60 \% 0.01 \mathrm{\mu g} \mathrm{m}^{-3}\right.$ and $40 \%$ $\left.10 \mu \mathrm{g} \mathrm{m}^{-3}\right)$, the optimization resulted in an absolute volatility error of less than $10 \%$ for all bins. The vaporization enthalpy was well estimated (relative error equal to $8 \%$ ), and the mass accommodation coefficient was estimated within a factor of 2 (0.97 instead of 0.5$)$. For Test 2 corresponding to multicomponent OA (10\% $0.1 \mu \mathrm{g} \mathrm{m}^{-3}, 30 \% 1 \mu \mathrm{g} \mathrm{m}^{-3}$ and $60 \% 10 \mu \mathrm{g} \mathrm{m}^{-3}$ ), the estimated volatility distribution had a different shape than the true one, with more material predicted for the bin of $1 \mu \mathrm{g} \mathrm{m}^{-3}$ (predicted mass fraction equal to 0.49 instead of 0.3 ), and less for the $10 \mu \mathrm{g} \mathrm{m}^{-3}$ bin (predicted mass fraction equal to 0.31 instead of 0.6 ). Also, some very low volatility material was estimated (predicted mass fraction equal to 0.07 while none was present). The vaporization enthalpy was estimated with a relative error equal to $40 \%$, and the accommodation coefficient was well estimated (0.72 instead of unity). For Test 3 with the case of one-component $\mathrm{OA}$ with a volatility of $1 \mu \mathrm{g} \mathrm{m}^{-3}$, the estimates of all properties were far from the truth. Most of the material $(88 \%)$ was estimated to be in the $0.1 \mu \mathrm{g} \mathrm{m}^{-3}$ bin instead of $1 \mu \mathrm{g} \mathrm{m}^{-3}$, and some material (12\%) was predicted in the highest volatility bin of $10 \mu \mathrm{g} \mathrm{m}^{-3}$. The estimated vaporization enthalpy was more than a factor of 2 higher than

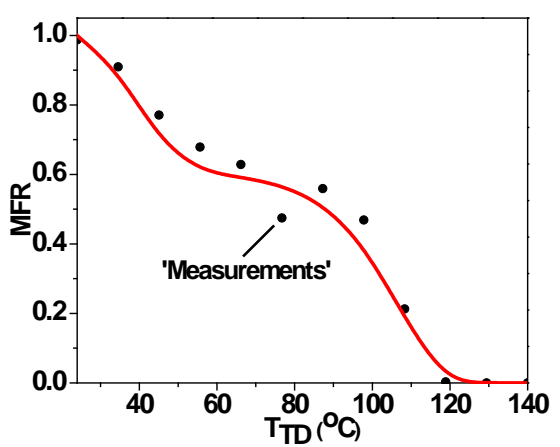

Figure 2. Typical example of "construction" of TD pseudo-data. The red line is the thermogram corresponding to the true properties of the aerosol, and the black dots correspond to the "measured" MFR versus $T_{\mathrm{TD}}$ for an aerosol consisting of two components: very low volatility material $\left(60 \% C^{*}=0.01 \mu \mathrm{g} \mathrm{m}^{-3}\right)$ and relatively high volatility material $\left(40 \% C^{*}=10 \mu \mathrm{g} \mathrm{m}^{-3}\right)$, with a vaporization enthalpy and a mass accommodation coefficient equal to $100 \mathrm{~kJ} \mathrm{~mol}^{-1}$ and 1, respectively. Twelve "measurements" were constructed for equally spaced temperatures between 24 and $140{ }^{\circ} \mathrm{C}$ by corrupting the correct values with random experimental errors.

the true value, and the estimated accommodation coefficient was a factor of 25 lower than it should be.

The results, using different initial guesses for the case of multiple-component OA (Test 2), are shown in Fig. 3. For an initial guess of [ $\left[\begin{array}{llll}0 & 0 & 0.3 & 0.7\end{array}\right]$ for the mass fractions of the volatility bins $\left(C^{*}=\left[\begin{array}{llll}0.01 & 0.1 & 1 & 10\end{array}\right] \mathrm{\mu g} \mathrm{m}^{-3}\right), 50 \mathrm{~kJ} \mathrm{~mol}^{-1}$ for the vaporization enthalpy and 0.5 for the accommodation coefficient, the shape of the volatility distribution was estimated correctly, but with significant errors of $0.1-0.2$ in the $0.1,1$ and $10 \mu \mathrm{g} \mathrm{m}^{-3}$ bins. The vaporization enthalpy estimation error was $24 \%$ and the estimated accommodation coefficient was 0.9 , close to the true value of unity. This is however a local minimum of the objective function. The global minimum (minimum error) was found when we used an initial guess of $\left[\begin{array}{llll}0.1 & 0.1 & 0.3 & 0.5\end{array}\right]$ for the mass fractions, $80 \mathrm{~kJ} \mathrm{~mol}^{-1}$ for $\Delta H_{\mathrm{vap}}$, and 0.2 for $a_{\mathrm{m}}$. The estimated OA volatility distribution, in this case, is shown in Fig. 3b. In this case, the shape of the volatility distribution is not correct, and there are errors in the mass fractions of the volatility bins as large as 0.3 . The estimated vaporization enthalpy and accommodation coefficient were similar to those of the previous guess, with a relative error of $35 \%$ for $\Delta H_{\mathrm{vap}}$. Due to the experimental error, the global minimum can correspond to volatility distributions that are far from the true values. We conclude that the optimization method may not be appropriate for the estimation of the volatility distribution, the vaporization enthalpy and the mass accommodation coefficient. It is also clear that we need an approach for estimating the corresponding uncertainties. 

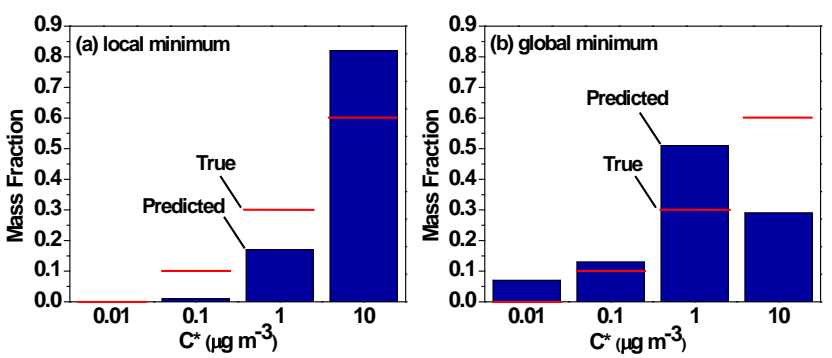

Figure 3. Estimated (bars) and true (red lines) volatility distribution for OA consisting of $10 \% C^{*}=0.1 \mu \mathrm{g} \mathrm{m}^{-3}, 30 \% 1 \mu \mathrm{g} \mathrm{m}^{-3}$, $60 \% 10 \mu \mathrm{g} \mathrm{m}^{-3}, \Delta H_{\text {vap }}=50 \mathrm{~kJ} \mathrm{~mol}^{-1}$ and $a_{\mathrm{m}}=1$, based on TD pseudo-data. (a) Solution corresponding to a local minimum of the objective function. The estimated vaporization enthalpy and accommodation coefficient are $\Delta H_{\mathrm{vap}}=38 \mathrm{~kJ} \mathrm{~mol}^{-1}$ and $a_{\mathrm{m}}=0.9$. (b) Solution for the global minimum. The estimated $\Delta H_{\mathrm{vap}}$ and $a_{\mathrm{m}}$ are $68 \mathrm{~kJ} \mathrm{~mol}^{-1}$ and 0.84 , respectively.

\subsection{Estimation of uncertainty}

In an effort to explore in more detail the solution space for the problem, we discretized the parameter space and simulated all combinations of volatilities, $\Delta H_{\mathrm{vap}}$ and $a_{\mathrm{m}}$. We used once more four bins for volatilities from $10^{-2}$ to $10 \mu \mathrm{g} \mathrm{m}^{-3}$, and varied the mass fraction of each bin from 0 to 1 with a step of 0.1 . The values used for $\Delta H_{\text {vap }}$ were from 20 to 200 , with discrete values of 20, 50, 80, 100, 150 and $200 \mathrm{~kJ} \mathrm{~mol}^{-1}$, and for $a_{\mathrm{m}}$, the values were from 0.01 (large mass resistance) to 1 (no mass resistance), with discrete values of $0.01,0.05$, $0.1,0.2,0.5$ and 1 . We also tried in our simulations other discretizations for the values of the vaporization enthalpy and the mass accommodation coefficient, and they did not affect the results. In the rest of the paper, the discretizations for the $\Delta H_{\mathrm{vap}}$ and the $a_{\mathrm{m}}$ described above will be used for all of the simulations. For each simulation, the percentage error was estimated from

$E_{i}=\frac{100}{n} \sqrt{\sum_{i}^{n}\left(\mathrm{MFR}_{i, \text { guess }}-\mathrm{MFR}_{i}\right)^{2}}$,

where $\mathrm{MFR}_{i, \text { guess }}$ is the MFR for a certain combination of parameters for data point $i$ (corresponding to a specific temperature), $\mathrm{MFR}_{i}$ is the "measured" MFR, and $n$ is the number of the different temperatures $T_{\mathrm{TD}}$ used in our "measurements".

After performing simulations for all combinations of all properties, we identified the combinations that led to small errors (less than $2 \%$ ). From these values, we then calculated a "best estimate" using the inverse error as a weighting factor:

$$
\bar{x}=\frac{\sum_{i}^{N}\left[\left(x_{i}\right) \cdot\left(\frac{1}{E_{i}}\right)\right]}{\sum_{i}^{N}\left[\frac{1}{E_{i}}\right]},
$$

where $x_{i}$ is the value of property $i$ (the mass fractions of the volatility bin $i$ or the vaporization enthalpy $\Delta H_{\text {vap }}$ or the accommodation coefficient $\left.\log \left(a_{\mathrm{m}}\right)\right)$.

We also calculated the uncertainty range for all three properties by calculating the standard deviation $(\sigma)$ of the corresponding values:

$\sigma=\sqrt{\frac{\sum_{i}^{N}\left[\left(\left(x_{i}-\bar{x}\right)^{2} \cdot\left(\frac{1}{E_{i}}\right)\right)\right]}{\sum_{i}^{N}\left[\frac{1}{E_{i}}\right]} .}$

The logarithms of the accommodation coefficient values were used in order to avoid negative accommodation coefficient values inside the uncertainty range. We report one standard deviation as the uncertainty range in the rest of the paper.

\section{Results}

The first parameter of the thermodenuder experiments explored was the number of measurements at different temperatures in the thermogram under consideration. In previous studies, thermodenuder measurements vary between 6 (An et al., 2007) and 12 measurements (Faulhaber et al., 2009).

A wide variety of cases of OA were tested during the simulations once more. The results for a multicomponent OA with mostly nonvolatile material $\left(80 \% 0.01 \mu \mathrm{g} \mathrm{m}^{-3}, 5 \%\right.$ $0.1 \mu \mathrm{g} \mathrm{m}^{-3}, 10 \% 1 \mu \mathrm{g} \mathrm{m}^{-3}$ and $5 \% 10 \mu \mathrm{g} \mathrm{m}^{-3}$ ), for the cases of 6 and 12 measurements, are given in Fig. 4 as a representative example. For the first experiment, with a small number of measurements (6 points), there is large uncertainty in the two least volatile bins (with a standard deviation up to 0.25 ). The uncertainty range in the least and most volatile bins ( 0.01 and $10 \mu \mathrm{g} \mathrm{m}^{-3}$ ) does not include the correct values for the distribution. In the second experiment, twice as many measurements were used (12 points), the estimated uncertainty range is smaller (the standard deviation of all the predicted mass fractions is less than 0.08), and it contains the correct volatility distribution. The relative error of the estimated $\Delta H_{\text {vap }}$ is $13 \%$, in both experiments. Finally, the $a_{\mathrm{m}}$ is underestimated for both experiments, but with the second experiment (using 12 measurements), the uncertainty range includes the correct value.

For cases of OA with more uniform volatility distributions (e.g., cases where the mass fraction varies less than 0.2 between the bins), the use of 12 measurements instead of 6 gave similar estimates for the three properties (volatility distribution, vaporization enthalpy and mass accommodation coefficient) and the same uncertainty ranges. In cases of extreme volatility distributions, where most material is in one or two volatility bins, as in the case of the example in Fig. 4, using more measurements resulted in better estimates and smaller 
Table 1. Values of the true and estimated properties (volatility distribution, vaporization enthalpy, accommodation coefficient) for three OA examples.

\begin{tabular}{|c|c|c|c|}
\hline & $\begin{array}{l}\text { Test } 1 \\
\text { OA with very low and } \\
\text { high volatility material }\end{array}$ & $\begin{array}{l}\text { Test } 2 \\
\text { Multiple- } \\
\text { component OA }\end{array}$ & $\begin{array}{l}\text { Test } 3 \\
\text { One- } \\
\text { component OA }\end{array}$ \\
\hline True values & $\begin{array}{l}C_{i}^{*}=\left[\begin{array}{llll}0.01 & 0.1 & 1 & 10\end{array}\right] \\
X_{i}=\left[\begin{array}{llll}0.6 & 0 & 0 & 0.4\end{array}\right] \\
\Delta H_{\mathrm{vap}}=100 \mathrm{~kJ} \mathrm{~mol}^{-1} \\
a_{\mathrm{m}}=0.5\end{array}$ & $\begin{array}{l}C_{i}^{*}=\left[\begin{array}{llll}0.01 & 0.1 & 1 & 10\end{array}\right] \\
X_{i}=\left[\begin{array}{llll}0 & 0.1 & 0.3 & 0.6\end{array}\right] \\
\Delta H_{\mathrm{vap}}=50 \mathrm{~kJ} \mathrm{~mol}^{-1} \\
a_{\mathrm{m}}=1\end{array}$ & $\begin{array}{l}C_{i}^{*}=\left[\begin{array}{llll}0.01 & 0.1 & 1 & 10\end{array}\right] \\
X_{i}=\left[\begin{array}{llll}0 & 0 & 1 & 0\end{array}\right] \\
\Delta H_{\mathrm{vap}}=80 \mathrm{~kJ} \mathrm{~mol}^{-1} \\
a_{\mathrm{m}}=1\end{array}$ \\
\hline Optimization results & 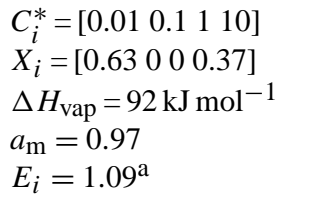 & 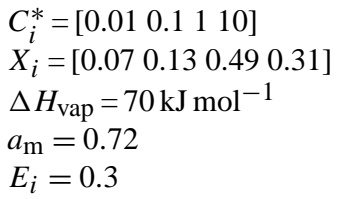 & 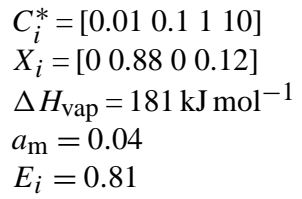 \\
\hline
\end{tabular}

a The error, given by Eq. (10), describes the quality of the fit.
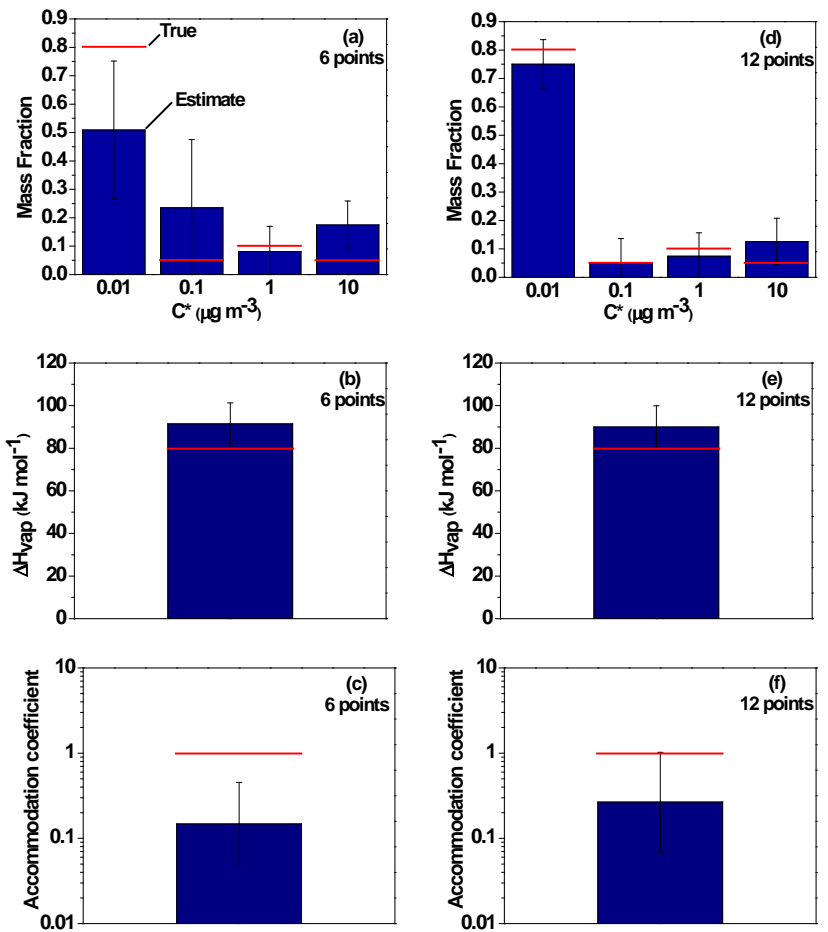

Figure 4. Estimated (bars) and true (red lines) parameter values for an OA with $80 \% 0.01 \mathrm{~g} \mathrm{~m}^{-3}, 5 \% 0.1 \mu \mathrm{g} \mathrm{m}^{-3}, 10 \% 1 \mathrm{gg} \mathrm{m}^{-3}$, and $5 \% 10 \mu \mathrm{g} \mathrm{m}^{-3}, \Delta H_{\mathrm{vap}}=80 \mathrm{~kJ} \mathrm{~mol}^{-1}$ and $a_{\mathrm{m}}=1$ for $6 \mathrm{mea}-$ surements, (a) volatility distribution, (b) $\Delta H_{\mathrm{vap}}$, and (c) $a_{\mathrm{m}}$, and using 12 measurements for (d) volatility distribution, (e) $\Delta H_{\mathrm{vap}}$, and (f) $a_{\mathrm{m}}$. The error bars represent the uncertainty of the estimated value.

uncertainty ranges than using only a small number of measurements.

In Fig. 5, we examine two more cases of OA with extreme volatility distributions using 12 pseudo-measurements. In the first test, which is the same OA as in Test 1 discussed in Sect. 2.2, the OA consists of two components: very low volatility material $\left(60 \% 0.01 \mu \mathrm{g} \mathrm{m}^{-3}\right)$ and high volatility material $\left(40 \% 10 \mu \mathrm{g} \mathrm{m}^{-3}\right)$. The estimated uncertainty range is large, especially for the two least volatile bins (with an uncertainty equal to 0.2 ), but it includes the actual volatility distribution. Also, the estimated volatility distribution has the correct shape. The estimated vaporization enthalpy has an error of $5 \%$, while the accommodation coefficient error is around $20 \%$.

In the second test, we assume that the OA consists of very low volatility material $\left(50 \% \quad 0.01 \mathrm{\mu g} \mathrm{m}^{-3}\right)$ and relatively high volatility material $\left(50 \% 1 \mu \mathrm{g} \mathrm{m}^{-3}\right)$. The shape of the volatility distribution of the OA is not captured by the inversion results, the estimated uncertainty range is large (the uncertainty of all the predicted mass fractions is around 0.2 ), and the uncertainty range does not contain the actual volatility distribution. The error of the estimated $\Delta H_{\mathrm{vap}}$ is $8 \%$. The accommodation coefficient is underpredicted by one order of magnitude (value equal to 0.15 instead of unity). The TD measurements are not sufficient in this case for the accurate estimation of the OA volatility distribution.

In order to evaluate how general the above results of the proposed volatility estimation method are, we performed additional tests using ten randomly generated volatility distributions. The sets of parameters used are shown in Table 2 . The ten first parameter sets have random OA volatility distributions, a vaporization enthalpy equal to $90 \mathrm{~kJ} \mathrm{~mol}^{-1}$ (chosen as a reasonable intermediate value between 20 and $200 \mathrm{~kJ} \mathrm{~mol}^{-1}$ ), and an accommodation coefficient of 0.1 (chosen as a medium mass resistance). Additional cases with either low (sets 11-13) or high mass transfer resistance (sets 14-16) and cases with low (sets 11 and 13) or higher vaporization enthalpies (sets 12, 15 and 16) were also examined.

The inversion results are shown in Table 3 . They include the average absolute errors for the VBS bins, the relative error $(\%)$ for the vaporization enthalpy, and the errors for $a_{\mathrm{m}}$ (in 
Table 2. Sets of random volatility distributions used for the evaluation of different inversion approaches.

\begin{tabular}{|c|c|c|c|c|c|c|}
\hline \multirow{2}{*}{$\begin{array}{c}\mathrm{OA} \\
\text { parameter set }\end{array}$} & \multicolumn{4}{|c|}{ Mass fraction } & \multirow{2}{*}{$\begin{array}{r}\Delta H_{\mathrm{vap}} \\
\left(\mathrm{kJ} \mathrm{mol}^{-1}\right)\end{array}$} & \multirow[b]{2}{*}{$a_{\mathrm{m}}$} \\
\hline & $0.01 \mu \mathrm{g} \mathrm{m}^{-3}$ & $0.1 \mu \mathrm{g} \mathrm{m}^{-3}$ & $1 \mu \mathrm{g} \mathrm{m}^{-3}$ & $10 \mu \mathrm{g} \mathrm{m}^{-3}$ & & \\
\hline 1 & 0.135 & 0.06 & 0.14 & 0.665 & 90 & 0.1 \\
\hline 2 & 0.45 & 0.04 & 0.315 & 0.195 & 90 & 0.1 \\
\hline 3 & 0.255 & 0.115 & 0.47 & 0.16 & 90 & 0.1 \\
\hline 4 & 0.235 & 0.045 & 0.025 & 0.695 & 90 & 0.1 \\
\hline 5 & 0.565 & 0.23 & 0.175 & 0.03 & 90 & 0.1 \\
\hline 6 & 0.105 & 0.21 & 0.59 & 0.095 & 90 & 0.1 \\
\hline 7 & 0.375 & 0.405 & 0.15 & 0.07 & 90 & 0.1 \\
\hline 8 & 0.375 & 0.095 & 0.07 & 0.46 & 90 & 0.1 \\
\hline 9 & 0.145 & 0.435 & 0.25 & 0.17 & 90 & 0.1 \\
\hline 10 & 0.245 & 0.085 & 0.08 & 0.59 & 90 & 0.1 \\
\hline 11 & 0.565 & 0.23 & 0.175 & 0.03 & 70 & 1 \\
\hline 12 & 0.565 & 0.23 & 0.175 & 0.03 & 140 & 1 \\
\hline 13 & 0.245 & 0.085 & 0.08 & 0.59 & 60 & 1 \\
\hline 14 & 0.245 & 0.085 & 0.08 & 0.59 & 120 & 0.01 \\
\hline 15 & 0.135 & 0.06 & 0.14 & 0.665 & 120 & 0.01 \\
\hline 16 & 0.105 & 0.21 & 0.59 & 0.095 & 140 & 0.01 \\
\hline
\end{tabular}
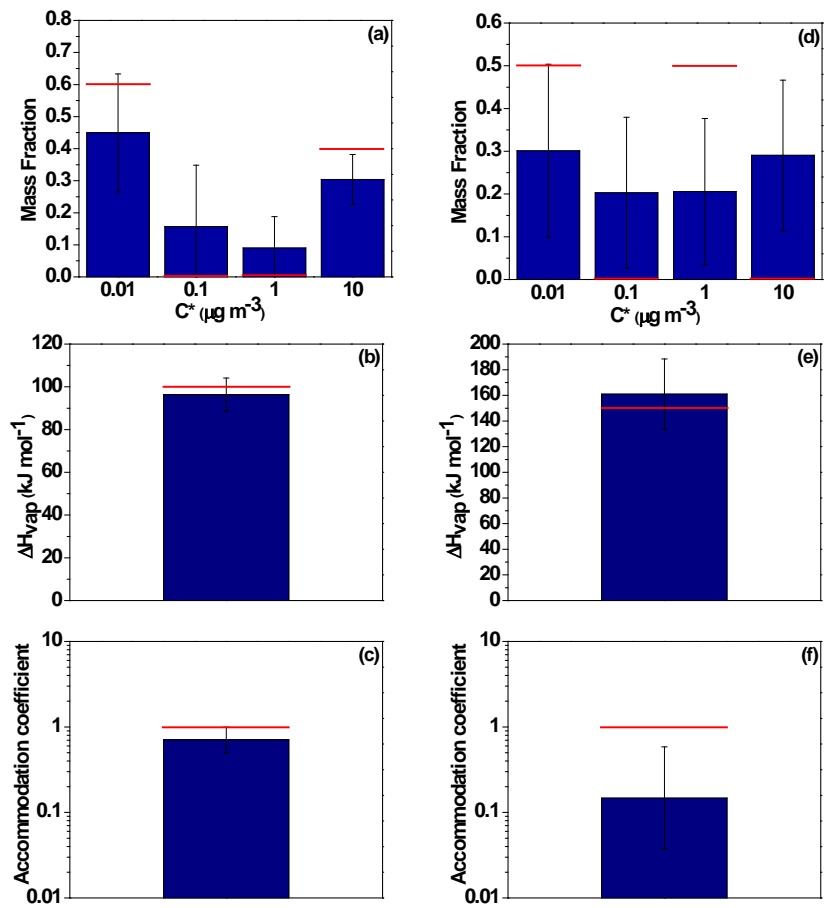

Figure 5. Estimated (bars) and true property values (red lines) using 12 TD measurements, for two types of OA. (a) Volatility distribution, (b) $\Delta H_{\mathrm{vap}}$, (c) $a_{\mathrm{m}}$ for OA, with $60 \% 0.01 \mu \mathrm{g} \mathrm{m} \mathrm{m}^{-3}$ and $40 \%$ $10 \mu \mathrm{g} \mathrm{m}^{-3}, \Delta H_{\mathrm{vap}}=100 \mathrm{~kJ} \mathrm{~mol}^{-1}$ and $a_{\mathrm{m}}=1$, and (d) volatility distribution, (e) $\Delta H_{\mathrm{vap}}$, and (f) $a_{\mathrm{m}}$ for OA, with $50 \% 0.01 \mu \mathrm{g} \mathrm{m}^{-3}$ and $50 \% 1 \mu \mathrm{g} \mathrm{m}^{-3} . \Delta H_{\mathrm{vap}}=150 \mathrm{~kJ} \mathrm{~mol}^{-1}$ and $a_{\mathrm{m}}=1$. The error bars represent the uncertainty of the estimated value. orders of magnitude). These results indicate that an accurate estimation of the OA volatility distribution is challenging in most cases. The volatility distribution was estimated with average absolute errors less than 0.1 for six out of the sixteen cases tested (sets 1, 4, 8, 910 and 13), and for the rest of the cases, the errors were up to 0.22 . The average relative error of the estimated $\Delta H_{\mathrm{vap}}$ was roughly $10 \%$. The error for the estimated accommodation coefficient varied from half to almost one and a half order of magnitude. Concerning the uncertainties (not shown), the uncertainty range of the volatility distribution in most of the cases was large (around 0.2). Exceptions are the cases with most material in the lowest and highest volatility bins, where the uncertainty range is $0.05-$ 0.15 . The uncertainty in the estimated $\Delta H_{\text {vap }}$ for most of the cases was around $20 \%$. The uncertainty in the estimated accommodation coefficient varied from less than one order of magnitude to two orders of magnitude.

Based on the above results, it is evident that it is very difficult to estimate the three properties accurately and with a small uncertainty range, since there are many combinations of properties than can lead to a thermogram quite similar to the one from the pseudo-experiment. So, even if the uncertainty estimation method proposed here is a step forward, the TD inversion results are either too uncertain or sometimes erroneous. The TD measurements using one residence time (17 s) are not sufficient to constrain the three properties, since equilibrium is not reached in most cases. It is clear that improvements in the volatility measurement approach itself are needed. A number of ideas are explored in the next section. These include using more than one TD residence time or using measurements on much longer timescales (e.g., isothermal dilution measurements). 


\section{Improvements in the volatility measurement method}

\subsection{Use of two residence times}

In order to improve the method for the estimation of the OA volatility distribution, $\Delta H_{\mathrm{vap}}$ and $a_{\mathrm{m}}$, we simulated "measurements" using two residence times (Lee et al., 2010), but with half the data points for each measurement (6 points for each residence time). We used two residence times of 17 and $34 \mathrm{~s}$. The estimation of the volatility distributions was improved, but the improvement in most cases was small to modest. For example, for the case of OA consisting of very low volatility material $\left(50 \% \quad 0.01 \mathrm{\mu g} \mathrm{m}^{-3}\right)$ and relatively high volatility material $\left(50 \% 1 \mu \mathrm{g} \mathrm{m}^{-3}\right)$, the correct volatility distribution was still not retrieved, the uncertainty range once again was large (equal to 0.2 ), and it did not contain the actual volatility distribution. The relative error of the estimated $\Delta H_{\text {vap }}$ was $6 \%$. The accommodation coefficient was underpredicted by one order of magnitude (value equal to 0.12 instead of unity).

We performed a number of tests with different OA systems. The use of two residence times resulted in improved estimates in some cases (e.g., single-component systems), but in the majority of the cases, the improvement was marginal. The results were often quite similar to those of the one residence time discussed above (with twice the data points). This was due to the fact that in most cases, the system is still far from equilibrium. We concluded that just doubling the residence time was not sufficient and that the residence time should increase to tens of minutes in most of the cases. This is very difficult though for continuous flow systems, so the next step was the exploration of the utility of evaporation measurements at much longer timescales than those that can be reached with a TD.

\subsection{Isothermal dilution experiments}

We tested the effectiveness of performing only isothermal dilution measurements instead of TD measurements. The isothermal evaporation of OA can take place in a smog chamber, and allows residence times of a few hours (Grieshop et al., 2009). The isothermal evaporation results at room temperature do not depend on $\Delta H_{\mathrm{vap}}$, but only on $C^{*}$ and $a_{\mathrm{m}}$. We assume that we dilute our OA samples during the injection in the chamber with a 10 -fold volume of clean air, so in this way, the initial gas and particle concentrations are lowered by a factor of 10 , and the system is out of equilibrium. We allow the aerosol to evaporate in the chamber for $2 \mathrm{~h}$ and assume that its concentration is measured every $10 \mathrm{~min}$. The error distribution used for the isothermal dilution is also based on the variability of the corresponding laboratory data. We "corrupted" the time-dependent mass transfer model predictions with a random error, assuming a uniform distribution with a standard deviation given by

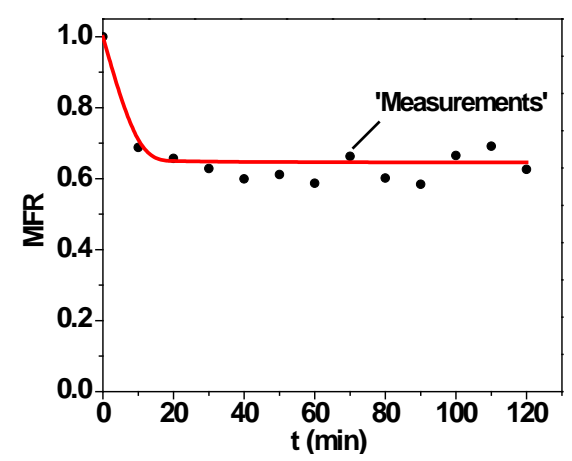

Figure 6. Isothermal dilution measurements (MFR as a function of time) for an aerosol with $60 \% 0.01 \mathrm{\mu g} \mathrm{m}^{-3}$ and $40 \% 10 \mathrm{\mu g} \mathrm{m}^{-3}$, $\Delta H_{\mathrm{vap}}=100 \mathrm{~kJ} \mathrm{~mol}^{-1}$ and $a_{\mathrm{m}}=1$. The red line corresponds to the true properties of the aerosol, and the black dots are the "measured" MFR values.

$\sigma=0.05 \cdot \mathrm{MFR}_{\text {true }}+0.03$

where $\mathrm{MFR}_{\text {true }}$ are the correct MFR values.

A typical set of isothermal dilution "measurements" is shown in Fig. 6. The organic particles reach equilibrium with the gas phase after approximately thirty minutes in this pseudo-experiment. The inversion results for the case of OA consisting of very low volatility material $\left(60 \% 0.01 \mu \mathrm{g} \mathrm{m}^{-3}\right)$ and high volatility material $\left(40 \% 10 \mu \mathrm{g} \mathrm{m}^{-3}\right)$, are shown in Fig. 7. The estimated volatility distribution had significant error, and the uncertainty was large (equal to 0.2 ). The accommodation coefficient was estimated within $20 \%$.

The dilution method was also used for the random sets of volatility distributions shown in Table 2, and the results are shown in Table 3. The average absolute errors for the VBS bins were around 0.2 , and the errors for the accommodation coefficient in all cases were up to one order of magnitude. Isothermal dilution did not consistently improve the estimated volatility distributions and the accommodation coefficient compared to the use of TD measurements. The uncertainty remains large, since there are still many combinations of the two properties that can lead to similar dilution curves.

\subsection{Combination of TD and isothermal dilution measurements}

We continued with the test of effectiveness of combining TD and isothermal dilution "measurements" using the same method as in Sect. 2.3. We used the same discretization for the values of the volatility distribution, the vaporization enthalpy and the accommodation coefficient, and constructed, using the evaporation model, the theoretical thermograms. Using random numbers based on a normal distribution (for the case of thermodenuder measurements) and uniform distribution (for the case of isothermal dilution 
Table 3. Results for the sets of random volatility distributions using different inversion approaches.

\begin{tabular}{|c|c|c|c|c|c|c|c|c|}
\hline \multirow[b]{2}{*}{$\begin{array}{c}\text { OA } \\
\text { parameter set }\end{array}$} & \multicolumn{3}{|c|}{ TD measurements } & \multicolumn{2}{|c|}{ Dilution measurements } & \multicolumn{3}{|c|}{ TD and dilution measurements } \\
\hline & $\begin{array}{r}\text { Average } \\
\text { absolute error } \\
\text { for VBS bins }\end{array}$ & $\begin{array}{r}\text { Relative } \\
\text { error }(\%) \text { for } \\
\Delta H_{\mathrm{vap}}\end{array}$ & $\begin{array}{r}\text { Error for } \\
a_{\mathrm{m}} \text { (orders } \\
\text { of magnitude) }\end{array}$ & $\begin{array}{r}\text { Average } \\
\text { absolute error } \\
\text { for VBS bins }\end{array}$ & $\begin{array}{r}\text { Error for } \\
a_{\mathrm{m}} \text { (orders } \\
\text { of magnitude) }\end{array}$ & $\begin{array}{r}\text { Average } \\
\text { absolute error } \\
\text { for VBS bins }\end{array}$ & $\begin{array}{r}\text { Relative } \\
\text { error }(\%) \\
\text { for } \Delta H_{\mathrm{vap}}\end{array}$ & $\begin{array}{r}\text { Error for } \\
a_{\mathrm{m}} \text { (orders } \\
\text { of magnitude) }\end{array}$ \\
\hline 1 & 0.05 & 6 & 0.43 & 0.13 & 0.39 & 0.02 & 11 & 0 \\
\hline 2 & 0.13 & 3 & 0.06 & 0.11 & 0.17 & 0.02 & 2 & 0.16 \\
\hline 3 & 0.1 & 8 & 0.1 & 0.51 & 0.19 & 0.07 & 2 & 0.02 \\
\hline 4 & 0.08 & 10 & 0.45 & 0.19 & 0.36 & 0.02 & 4 & 0.1 \\
\hline 5 & 0.14 & 4 & 0.28 & 0.12 & 0.44 & 0.14 & 0.7 & 0.46 \\
\hline 6 & 0.1 & 10 & 0.02 & 0.15 & 0.02 & 0.07 & 10 & 0.04 \\
\hline 7 & 0.14 & 7 & 0.13 & 0.06 & 0.19 & 0.07 & 2 & 0.05 \\
\hline 8 & 0.07 & 4 & 0.17 & 0.18 & 0.34 & 0.04 & 0.9 & 0.06 \\
\hline 9 & 0.09 & 3 & 0.04 & 0.07 & 0.21 & 0.09 & 0.1 & 0.34 \\
\hline 10 & 0.06 & 11 & 0.45 & 0.16 & 0.46 & 0.06 & 11 & 0.37 \\
\hline 11 & 0.14 & 14 & 1.17 & 0.12 & 1.06 & 0.1 & 14 & 0.77 \\
\hline 12 & 0.11 & 14 & 0.95 & 0.12 & 1.06 & 0.06 & 23 & 0.96 \\
\hline 13 & 0.06 & 2 & 0.3 & 0.07 & 0.17 & 0.08 & 0.04 & 0.24 \\
\hline 14 & 0.18 & 25 & 1.22 & 0.2 & 0.75 & 0.33 & 17 & 1 \\
\hline 15 & 0.22 & 14 & 1.12 & 0.21 & 0.83 & 0.3 & 8 & 1.22 \\
\hline 16 & 0.11 & 11 & 0.63 & 0.18 & 0.50 & 0.17 & 4 & 0.32 \\
\hline
\end{tabular}

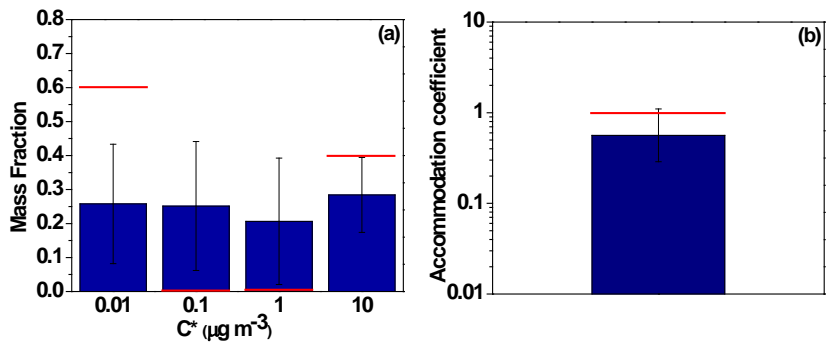

Figure 7. Estimated (bars) volatility distribution and accommodation coefficient and true (red lines) values using isothermal dilution "measurements", for an OA with $60 \% 0.01 \mu \mathrm{g} \mathrm{m}{ }^{-3}$ and $40 \%$ $10 \mu \mathrm{g} \mathrm{m}^{-3} ; \Delta H_{\text {vap }}=100 \mathrm{~kJ} \mathrm{~mol}^{-1}$ and $a_{\mathrm{m}}=1$. (a) Volatility distribution and (b) $a_{\mathrm{m}}$.

measurements), we produced pseudo-measurements for the different experiments. For the resulting 24 measurements (12 for each TD and dilution pseudo-experiment), we then performed the error minimization with the percentage error given by Eq. (10), treating equally the TD and isothermal dilution measurements. In the case of Test 1 (Table 1) shown in Fig. 8, the estimated volatility distribution has the correct shape, and the corresponding uncertainty range is small (uncertainty less than or equal to 0.1 ). The $\Delta H_{\text {vap }}$ and the $a_{\mathrm{m}}$ were estimated within a few percent. In another challenging test (Fig. 9), the shape of the volatility distribution is again predicted correctly. The estimated value of the vaporization enthalpy has an error of only $7 \%$, and the estimated accommodation coefficient is 0.4 instead of unity.

We also repeated all the tests of Table 2. The results are shown in Table 3. In $70 \%$ of the cases, the volatility distribution was reproduced with absolute errors less than 0.1 . The average relative error of the estimated
$\Delta H_{\text {vap }}$ was roughly $7 \%$. The error for the estimated accommodation coefficient for the cases of OA varied from less than half an order of magnitude up to one order of magnitude. The uncertainties (not shown) for the volatility distribution in $70 \%$ of the cases were not higher than $0.05-0.1$. The uncertainties for the vaporization enthalpy were around $10 \%$. The accommodation coefficient, for the cases of OA with a value equal to 0.1 , had an uncertainty of half an order of magnitude. For cases where the accommodation coefficient was equal to unity, it was underpredicted, with an uncertainty varying from half an order of magnitude (set 13), to one order of magnitude (set 11), to two orders of magnitude (set 12). For the cases of OA (sets 14 to 16) where the accommodation coefficient is equal to 0.01 , it was overestimated by up to one order of magnitude.

Problems appeared in the three cases (sets 5, 9, and 13) in which less than $20 \%$ of the OA evaporated, and in the three cases where equilibrium was not reached (sets 14, 15, and 16). Using a higher initial dilution (100 times dilution), the actual volatility distribution was captured in sets 9 and 13 , with uncertainties equal to 0.2 and 0.1 , respectively. Results for set 5 improved marginally, because further evaporation could not be achieved due to the large amount of nonvolatile material in the OA. The longer residence times improved the accuracy of the estimated volatility distributions (errors less than 0.1). The errors in $\Delta H_{\text {vap }}$ and the accommodation coefficient were also reduced in all cases.

Summarizing, using both TD and dilution experiments reproduced volatility distributions with average uncertainties between 0.05 and 0.1 for most cases, provided that more than $20 \%$ or so of the aerosol evaporated during dilution and that the system had enough time to come close to equilibrium. The vaporization enthalpy was estimated with average errors 

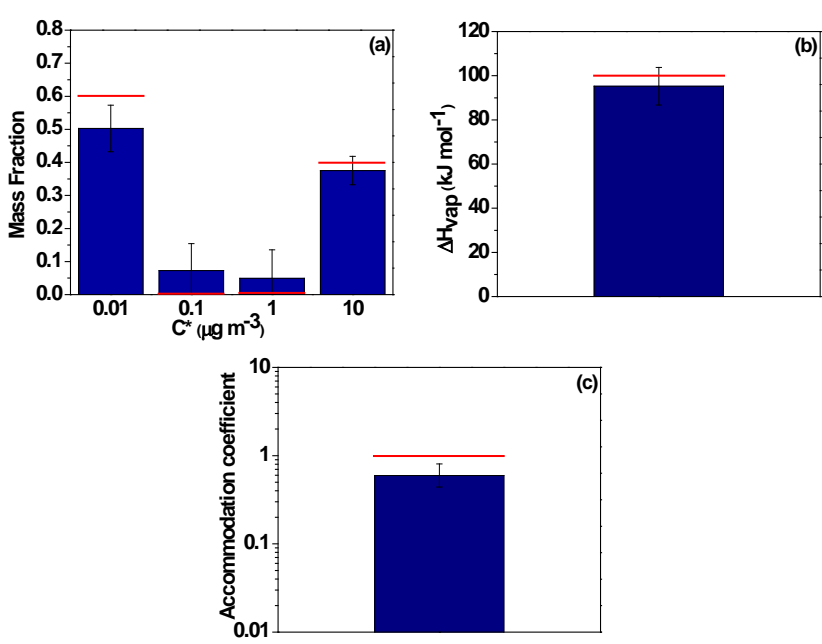

Figure 8. Estimated (bars) and true (red lines) parameter values combining TD and isothermal dilution measurements, for an OA with $60 \% 0.01 \mu \mathrm{g} \mathrm{m}^{-3}$ and $40 \% 10 \mu \mathrm{g} \mathrm{m}^{-3}, \Delta H_{\mathrm{vap}}=$ $100 \mathrm{~kJ} \mathrm{~mol}^{-1}$ and $a_{\mathrm{m}}=1$ for (a) volatility distribution, (b) $\Delta H_{\mathrm{vap}}$, and (c) $a_{\mathrm{m}}$.

less than $10 \%$ in most cases. Estimation of the accommodation coefficient was more challenging than the other parameters. Problems occur mostly when evaporation in dilution experiments is less than $20 \%$, or when equilibrium is not reached.

\section{Conclusions}

Multiple combinations of parameters $\left(C^{*}, \Delta H_{\mathrm{vap}}, a_{\mathrm{m}}\right)$ can lead to practically indistinguishable thermograms during TD measurements. The estimated volatility distribution, based on the minimum error, can be wrong by several orders of magnitude due to the multiple solutions that exist, leading to multiple local minima of the objective function. We introduce a new method combining forward modeling, introduction of experimental error and inverse modeling with error minimization for the interpretation of existing TD measurements. With this method, using an ensemble of "best solutions", we were able to calculate a best estimate and an uncertainty range for the estimated volatility distribution, the vaporization enthalpy and the accommodation coefficient. We show that this uncertainty range is often large and sometimes does not even include the true value of the properties, with the exception in the estimation of the vaporization enthalpy, where the errors are around 5-20\% in most cases tested.

Experimental approaches that would improve the method were explored. The performance of TD measurements under multiple residence times results in a small to modest improvement in the results, since equilibrium is still not reached. The idea of using experiments on a totally longer timescale in order to achieve equilibrium was then examined
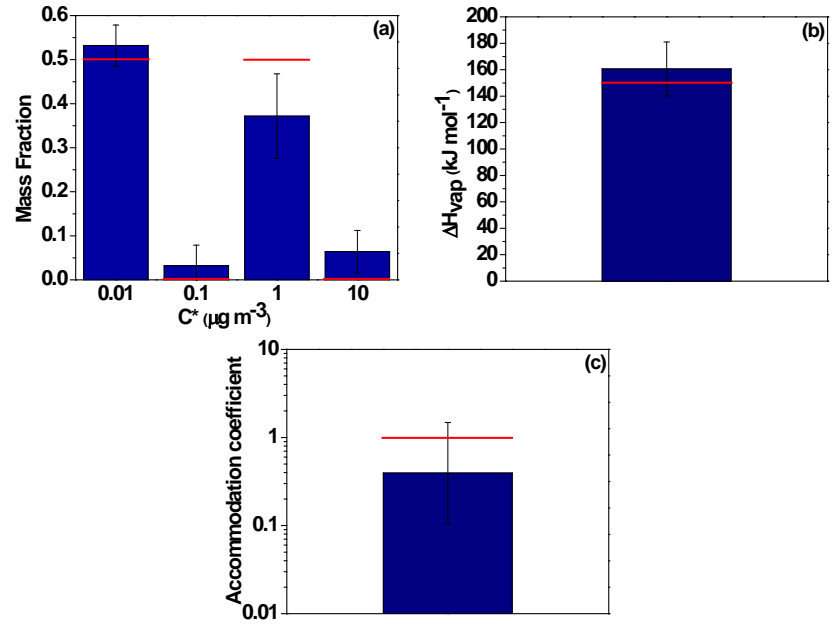

Figure 9. Estimated (bars) and true (red lines) parameter values combining TD and isothermal dilution measurements, for an OA with $50 \% 0.01 \mu \mathrm{g} \mathrm{m}^{-3}$ and $50 \% 1 \mu \mathrm{g} \mathrm{m}^{-3}, \Delta H_{\mathrm{vap}}=150 \mathrm{~kJ} \mathrm{~mol}^{-1}$ and $a_{\mathrm{m}}=1$ for (a) volatility distribution, (b) $\Delta H_{\mathrm{vap}}$, and (c) $a_{\mathrm{m}}$.

with the use of dilution measurements. Use of isothermal dilution on its own instead of TD measurements usually leads to worse estimates of the volatility distribution compared to the TD. However, combining both TD and isothermal dilution measurements leads to promising results in the majority of the cases. Cases for which problems remain include those in which the OA does not come close to equilibrium after dilution, or when the corresponding evaporated fraction is less than $20 \%$. Increased dilution and longer residence times can help in these cases. The approach combining TD and isothermal dilution measurements is recommended for future studies of OA volatility in both the lab and the field.

Acknowledgements. This research was supported by the ESFNRSF ARISTEIA grant ROMANDE, the US Department of Energy, and the FP7 IDEAS ATMOPACS project.

Edited by: J. Schneider

\section{References}

An, W. J., Pathak, R. K., Lee, B. H., and Pandis, S. N.: Aerosol volatility measurement using an improved thermodenuder: Application to secondary organic aerosol, J. Aerosol. Sci., 38, 305314, doi:10.1016/j.jaerosci.2006.12.002, 2007.

Burtscher, H., Baltensperger, U., Bukowiecki, N., Cohn, P., Huglin, C., Mohr, M., Matter, U., Nyeki, S., Schmatloch, V., Streit, N., and Weingartner, E.: Separation of volatile and nonvolatile aerosol fractions by thermodesorption: instrumental development and applications, J. Aerosol Sci., 32, 427-442, 2001.

Cappa, C. D.: A model of aerosol evaporation kinetics in a thermodenuder, Atmos. Meas. Tech., 3, 579-592, doi:10.5194/amt3-579-2010, 2010. 
Cappa, C. D. and Jimenez, J. L.: Quantitative estimates of the volatility of ambient organic aerosol, Atmos. Chem. Phys., 10, 5409-5424, doi:10.5194/acp-10-5409-2010, 2010.

Cappa, C. D. and Wilson, K. R.: Evolution of organic aerosol mass spectra upon heating: implications for OA phase and partitioning behavior, Atmos. Chem. Phys., 11, 1895-1911, doi:10.5194/acp11-1895-2011, 2011.

Chen, N. H. and Othmer, D. F.: New generalized equation for gas diffusion coefficient, J. Chem. Eng. Data, 7, 37-41, 1962.

Donahue, N. M., Robinson, A. L., Stanier, C. O., and Pandis, S. N.: Coupled partitioning, dilution, and chemical aging of semivolatile organics, Environ. Sci. Technol., 40, 2635-2643, 2006.

Donahue, N. M., Kroll, J. H., Pandis, S. N., and Robinson, A. L.: A two-dimensional volatility basis set - Part 2: Diagnostics of organic-aerosol evolution, Atmos. Chem. Phys., 12, 615-634, doi:10.5194/acp-12-615-2012, 2012.

Engler, C., Rose, D., Wehner, B., Wiedensohler, A., Brüggemann, E., Gnauk, T., Spindler, G., Tuch, T., and Birmili, W.: Size distributions of non-volatile particle residuals $\left(D_{p}<800 \mathrm{~nm}\right)$ at a rural site in Germany and relation to air mass origin, Atmos. Chem. Phys., 7, 5785-5802, doi:10.5194/acp-7-5785-2007, 2007.

Epstein, S. A., Riipinen, I., and Donahue, N. M.: A semiempirical correlation between enthalpy of vaporization and saturation concentration for organic aerosol, Environ. Sci. Technol., 44, 743748, 2010

Faulhaber, A. E., Thomas, B. M., Jimenez, J. L., Jayne, J. T., Worsnop, D. R., and Ziemann, P. J.: Characterization of a thermodenuder-particle beam mass spectrometer system for the study of organic aerosol volatility and composition, Atmos. Meas. Tech., 2, 15-31, doi:10.5194/amt-2-15-2009, 2009.

Fuchs, N. A. and Sutugin, A. G.: Highly Dispersed Aerosols, Ann Arbor Science Publishers, Ann Arbor, London, 1970.

Fuentes, E. and McFiggans, G.: A modeling approach to evaluate the uncertainty in estimating the evaporation behaviour and volatility of organic aerosols, Atmos. Meas. Tech., 5, 735-757, doi:10.5194/amt-5-735-2012, 2012.

Grieshop, A. P., Miracolo, M. A., Donahue, N. M., and Robinson, A. L.: Constraining the volatility distribution and gasparticle partitioning of combustion aerosols using isothermal dilution and thermodenuder measurements, Environ. Sci. Technol., 43, 4750-4756, doi:10.1021/es8032378, 2009.

Huffman, J. A., Docherty, K. S., Mohr, C., Cubison, M. J., U1brich, I. M., Ziemann, P. J., Onasch, T. B., and Jimenez, J. L.: Chemically-resolved volatility measurements of organic aerosol from different source, Environ. Sci. Technol., 43, 5351-5357, 2009.

IPCC: Climate Change: The Physical Science Basis - Contribution of Working Group I to the Fourth Assessment Report of the Intergovernmental Panel on Climate Change, edited by: Solomon, S., Qin, D., and Manning, M., Cambridge University Press, Cambridge, 996 pp., 2007.

Jonsson, A. M., Hallquist, M., and Saathoff, H.: Volatility of secondary organic aerosols from the ozone initiated oxidation of apinene and limonene, J. Aerosol Sci., 38, 843-852, 2007.

Kalberer, M., Paulsen, D., Sax, M., Steinbacher, M., Dommen, J., Prevot, A. S. H., Fisseha, R., Weingartner, E., Frankevich, V., Zenobi, R., and Baltensperger, U.: Identification of polymers as major components of atmospheric organic aerosols, Science, 303, 1659-1662, 2004

Lee, B. H., Kostenidou, E., Hildebrandt, L., Riipinen, I., Engelhart, G. J., Mohr, C., DeCarlo, P. F., Mihalopoulos, N., Prevot, A. S. H., Baltensperger, U., and Pandis, S. N.: Measurement of the ambient organic aerosol volatility distribution: application during the Finokalia Aerosol Measurement Experiment (FAME2008), Atmos. Chem. Phys., 10, 12149-12160, doi:10.5194/acp10-12149-2010, 2010.

Lee, B. H., Pierce, J. R., Engelhart, G. J., and Pandis, S. N.: Volatility of secondary organic aerosol from the ozonolysis of monoterpenes, Atmos. Environ., 45, 2443-2452, 2011.

Nel, A.: Air pollution-related illness: Effects of particles, Science, 308, 804-806, doi:10.1126/science.1108752, 2005.

Paciga, A. and Pandis, S. N.: Reduction of the volatility of atmospheric diacids due to their reactions with ammonia, submitted, 2014.

Pathak, R. K., Presto, A. A., Lane, T. E., Stanier, C. O., Donahue, N. M., and Pandis, S. N.: Ozonolysis of $\alpha$-pinene: parameterization of secondary organic aerosol mass fraction, Atmos. Chem. Phys., 7, 3811-3821, doi:10.5194/acp-7-3811-2007, 2007.

Pope, C. A. and Dockery, D. W.: Health effects of fine particulate air pollution: Lines that connect, J. Air Waste Manage. Assoc., 56, 709-742, 2006.

Riipinen, I., Pierce, J. R., Donahue, N. M., and Pandis, S. N.: Equilibration time scales of organic aerosol inside thermodenuders: Kinetics versus equilibrium thermodynamics, Atmos. Environ., 44, 597-607, 2010.

Saleh, R., Walker, J., and Khlystov, A.: Determination of saturation pressure and enthalpy of vaporization of semi-volatile aerosols: The integrated volume method, J. Aerosol. Sci., 39, 876-887, doi:10.1016/j.jaerosci.2008.06.004, 2008.

Saleh, R., Shihadeh, A., and Khlystov, A.: On transport phenomena and equilibration time scales in thermodenuders, Atmos. Meas. Tech., 4, 571-581, doi:10.5194/amt-4-571-2011, 2011.

Saleh, R., Khlystov, A., and Shihadeh, A.: Determination of evaporation coefficients of ambient and laboratory-generated semivolatile organic aerosols from phase equilibration kinetics in a thermodenuder, Aerosol Sci. Technol., 46, 22-30, 2012.

Seinfeld, J. H. and Pandis, S. N.: Atmospheric Chemistry and Physics, 2nd Edn., John Wiley and Sons, Hoboken, New Jersey, USA, 2006.

Stanier, C. O., Donahue, N., Pandis, S. N.: Parameterization of secondary organic aerosol mass fractions from smog chamber data, Atmos. Environ., 42, 2276-2299, 2008.

Wehner, B., Philippin, S., and Wiedensohler, A.: Design and calibration of a thermodenuder with an improved heating unit to measure the size-dependent volatile fraction of aerosol particles, J. Aerosol Sci., 33, 1087-1093, 2002.

Wehner, B., Philippin, S., Wiedensohler, A., Scheer, V., and Vogt, R.: Variability of non-volatile fractions of atmospheric aerosol particles with traffic influence, Atmos. Environ., 38, 6081-6090, 2004. 
Zhang, Q., Jimenez, J. L., Canagaratna, M. R., Allan, J. D., Coe, H., Ulbrich, I., Alfarra, M. R., Takami, A., Middlebrook, A. M., Sun, Y. L., Dzepina, K., Dunlea, E., Docherty, K., DeCarlo, P. F., Salcedo, D., Onasch, T., Jayne, J. T., Miyoshi, T., Shimono, A., Hatakeyama, S., Takegawa, N., Kondo, Y., Schneider, J., Drewnick, F., Borrmann, S., Weimer, S., Demerjian, K., Williams, P., Bower, K., Bahreini, R., Cottrell, L.,
Griffin, R. J., Rautiainen, J., Sun, J. Y., Zhang, Y. M., and Worsnop, D. R.: Ubiquity and dominance of oxygenated species in organic aerosols in anthropogenically-influenced Northern Hemisphere midlatitudes, Geophys. Res. Lett., 34, L13801, doi:10.1029/2007GL029979, 2007. 